\title{
UM OLHAR PARA A DINÂMICA DO COORDENADOR DE GRUPOS ${ }^{1}$
}

\author{
A SIGHTING INTO THE GROUP LEADER DINAMICS \\ UN OLHAR EN LA DINÁMICA DEL LIDER DE LO GRUPO
}

\section{Kátya Alexandrina Matos Barreto Mota ${ }^{2}$, Denize Bouttelet Munari ${ }^{3}$}

RESUMO: No mundo contemporâneo a utilização de grupos enquanto estratégia na atenção em saúde e em atividades do ensino é cada vez mais utilizado, considerando inclusive as propostas oficiais do Ministério da Saúde e da Educação. Assim, o domínio dessa tecnologia pelos profissionais como fundamento para guiar suas ações assistenciais e gerenciais, torna-se, a cada dia de maior importância. Neste artigo de atualização propomos desenvolver alguns aspectos sobre os pressupostos teóricos e dilemas do coordenador de grupos, assim como apontar elementos que possam ajudar os profissionais que têm no grupo seu campo de trabalho. $O$ texto aborda também a organização do setting grupal, o manejo das situações previsíveis, a administração do tempo, manejo de conflitos do grupo e o poder do contrato grupal. A essência do texto é ancorada no principal dilema do coordenador de grupo, que é encontrar a medida adequada, ou seja, equilíbrio para fazer intervenções sobre os conteúdos que emergem na dinâmica grupal, centradas no contexto científico e no emocional que surgem do contato com o grupo. Neste intervalo entre a prática e a teoria, entre o profissional e 0 pessoal é que acreditamos encontrar o equilíbrio. Nesse sentido, é fundamental ao coordenador a noção da complexidade grupal, para que diante de sua singularidade possa viver o grupo e tudo o que dele emana.

PALAVRAS - CHAVE: Estrutura de Grupo; Recursos Humanos em Saúde; Grupos de Treinamento e Sensibilização; Processos Grupais.

ABSTRACT: Nowadays we are living the age of the group as a strategy in health assistance such as in educational activities, considering official proposals of both Ministries of Health and Education. Thus, to domain this technology by the professionals as a background to guide their assistance and managing actions becomes, each day more important. In this updating article, we consider to develop some aspects of theoretical presupposes and group coordinator dilemmas, as well as pointing elements that can help the professionals who have in the group their field of work. The text also approaches the group setting organization, the handling of preview situations, the time administration, the handling of the group conflicts and the power of the group contract. The essence of this text is anchored in the main group coordinator dilemma that is to find the measure adjustment, or either, balance to do interventions on the contents that emerge from the group dynamics, centered in the scientific and emotional contexts which comes from the work with the group. In this interval between theory and practice, the professional and the personal is where we believe is possible to find the balance. In this way, the notion of the group complexity is basic to the coordinator, so that ahead of its singularity it can live the group and everything what emanates from it.

KEY WORDS: Group Structure; Health Manpower; Sensitivity Training Group; Group Processes.

EXTRACTO: Hoy en día vivimos un tiempo en que el grupo es una estrategia en la asistencia en salud y en actividades educativas, considerando las proposiciones oficiales de los Ministerios de la Salud y de la Educación. Así, para el dominio de esta tecnología por los profesionales como base para la asistencia e administrar las acciones tornase, cada día más importante. En este artículo de actualización, proponemos desarrollar algunos aspectos teóricos y dilemas del coordinador del grupo, así como señalar elementos que pueden ayudar a los profesionales que tienen en el grupo su campo del trabajo. En el texto también discurre acerca de la organización del setting grupal, el manejo d las situaciones previsibles, la administración del tiempo, el manejo de conflictos del grupo e el poder del contracto grupal.
1. Texto produzido com apoio do Núcleo de Estudos e Pesquisas em Saúde Integral da Faculdade de Enfermagem da Universidade Federal de Goiás (NEPSI/FEN/UFG) em parceria com a Sociedade Brasileira de Psicoterapia, Psicodrama e Dinâmica de Grupo (SOBRAP/GOIÁS).

2 Psicóloga, Didata da Sociedade Brasileira de Psicoterapia, Psicodrama e Dinâmica de Grupo (SOBRAP/GOIÁS). Especialista em Gestão e Consultoria de Grupos. Professora Convidada do Departamento Psicologia da Universidade Católica de Goiás. Professora da Faculdade Cambury. Mestranda em Psicologia Social pela UCG. Goiânia, GO. E-mail: katyadesenvolverh@hotmail.com

${ }^{3}$ Enfermeira, Doutora em Enfermagem. Professora Titular da Faculdade de Enfermagem da Universidade Federal de Goiás. Especialista em Gestão e Consultoria de Grupos pela SOBRAP/GOIÁS. Goiânia, GO. E-mail: denize@fen.ufg.br 
La esencia de este texto se ancla en el principal dilema del coordinador del grupo que es encontrar el ajuste de la medida adecuada, o mejor, el equilibrio para hacer intervenciones en el contenido que emerge de la dinámica del grupo, centrado en los contextos científicos y emocionales que vienen del trabajo con el grupo. En este intervalo entre la teoría y la práctica, el profesional y el personal es donde creemos ser posibles encontrar el equilibrio. De esta

\section{INTRODUÇÃO}

A coordenação de grupos é uma arte e uma ciência, na medida em que exige sensibilidade, criatividade, emoção e ao mesmo tempo, teoria, técnica e compromisso com o cuidado humano. O estudo e pesquisa sobre os grupos, em particular, sobre os fundamentos da coordenação são fundamentais para o desenvolvimento dos aportes teóricos para melhor compreensão dos fenômenos grupais e suas vicissitudes (OSÓRIO, 2000).

Em busca do aprofundamento e ampliação desse campo de conhecimento é que nos propusemos o desenvolvimento desse estudo, cujo objetivo é apresentar algumas reflexões sobre os pressupostos e principais dilemas do coordenador de grupos e apontar alguns elementos que possam ajudar os profissionais que tem no grupo seu campo de trabalho.

O principal dilema do coordenador de grupo é encontrar a medida adequada para fazer intervenções sobre os conteúdos que emergem na dinâmica grupal, que engloba o foca no contexto científico, mas também no emocional que surgem do contato com o grupo. É essencial iniciar um trabalho com grupos de forma receptiva e aberta. Neste intervalo entre a prática e a teoria, entre 0 profissional e o pessoal é que podemos buscar o equilíbrio.

O lugar que o coordenador ocupa no grupo é de autoridade e sua figura é percebida no sistema simbólico grupal como um modelo a ser seguido e, este, desempenha um papel fundamental nas trocas e interações do universo que estar estruturando, organizando seus processos internos e formando sua identidade (ANZIEU, 1983).

O exercício de coordenar grupos pressupõe um desenho de autoridade que permanece no espaço multidimensional, mas que permite ao grupo fluir num movimento de construção da própria identidade, estabelecer laços, criar vínculos, aproximar dos semelhantes e constatar as diferenças (ANDALÓ, 2001; 2006). A sinergia grupal deve surgir dentro do próprio grupo. A experiência com os diversos tipos de grupos e diferentes situações, indica ao coordenador que sem impor, mas já utilizando um saber, o bom senso, a flexibilidade e a capacidade de ouvir, assegure a totalidade do grupo e a individualidade de cada ser manera, la noción de la complejidad del grupo es básica al coordinador, de modo que delante de su singularidad pueda vivir el grupo y todo qué emana de él.

PALABRAS ClAVE: Estructura del Grupo; Recursos Humanos en Salud; Grupos de Entrenamiento Sensitivo; Procesos Grupales.

que constitui o universo grupal. Neste contexto, a palavra respeito adquire uma importância vital, sendo priorizada como o princípio a ser adotado. Respeito às limitações, histórias, tradições, ritos, conquistas, saber, experiências e competências de cada membro no grupo (LEWIN, 1948).

\section{OS PRINCIPAIS PRESSUPOSTOS TEÓRICOS DA POSTURA DE UM COORDENADOR DE UM PROCESSO GRUPAL}

De modo geral e partindo das contribuições de MOSCOVICI (2001); VECCHIO (1975); BECHELLI \& SANTOS $(2001,2002)$ podemos dizer que são posturas esperadas pelo coordenador de grupos:

- A competência técnica que seria o domínio dos conceitos científicos da área, dos instrumentos a serem aplicados e de habilidade para intervir e administrar as questões grupais, de tal forma que as pessoas envolvidas continuem trabalhando efetivamente;

- A competência interpessoal para conduzir o grupo com espontaneidade, propiciando um ambiente propício à integração grupal;

- A responsabilidade ética com o grupo, que deve ser de uma dimensão humanística, anti autoritária e universal. A ética é inalienável, não se flexibiliza, não se desdobra, não existe nenhum talvez, nem se conjuga o verbo no passado e nem no futuro, está sempre no tempo presente. É uma questão de atitude;

- Procura-se colocar entre parênteses os conceitos adquiridos durante a formação acadêmica, para não enquadrar as pessoas em determinadas teorias prontas, acabadas e padronizados, marginalizando-as.

- Como profissional não é possível emitir diagnósticos e leituras que generalizam o comportamento do grupo, porque cada um é singular é ímpar;

- Evitar os juízos para científicos e observações provenientes das crenças populares e mitos que não condizem com o universo grupal;

- Não permitir que idéias preconcebidas de uma racionalidade unidimensional decorrentes de seu convívio social interfiram em sua percepção grupal, como: idade, sexo, cor, raça, cultura, religião, traços físicos, trejeitos pessoais, outros; 
- Orientar-se por meio do próprio tempo das pessoas, evitando atropelo e acima de tudo, observar os ritmos, perceber os rituais e as crenças inerentes ao grupo;

- É fundamental evitar os conceitos, os preconceitos e os para-conceitos, o que torna vital a necessidade de colocar em parêntese as emoções, ansiedades de expor um discurso, o temor de errar, o desejo de não perder o (s) membro (s) do grupo, o temor da crítica dos participantes, o medo de não obter uma avaliação positiva do trabalho realizado, o receio de perder toda a afetividade nascida do encontro e articulada na relação com o grupo.

Todos estes fatores citados são atitudes esperadas e cuidados necessários para não obscurecer, nem dificultar a dinâmica do grupo e, conseqüentemente, facilitar a caminhada na busca de ampliar e aperfeiçoar os conhecimentos, desenvolver as potencialidades, promover a integração e romper paradigmas, possibilitando mudanças, sem impedir o crescimento intra, inter e grupal. O papel do coordenador é intervir, lidando com a dialética dos elementos grupais, trazendo-os para uma dimensão transparente, plana, horizontal, de modo que todos tenham acesso às questões que estão ocorrendo no universo grupal.

Isso significa pontuar os elementos objetivos e a manifestação da subjetividade que se encontram numa dimensão entre o invisível e o latente, que reflete nas atitudes, valores, crenças, mitos que evidenciam comportamentos arraigados, hábitos, ritos, sistema de comunicação, mitos e lideranças presentes no contexto grupal.

A intervenção do coordenador após um fato ocorrido ou uma vivência grupal é denominada por MOSCOVICI (1965) como ciclo do processamento. Esse momento, na visão da autora é de fundamental importância, pois:

1) oportuniza que os membros do grupo vivenciem uma determinada situação e tomem consciência de seus sentimentos relativos ao tema proposto;

2) correlaciona a teoria com o que foi vivenciado, de uma forma ilustrativa, sem julgar ou mesmo concluir, permitindo que cada membro do grupo sinta e perceba as emoções suscitadas desta experiência. A leitura verticalizada que 0 coordenador faz da situação permite a reflexão dos aspectos perceptíveis e significativos no e para o grupo.

3) abre oportunidades para o crescimento pessoal quando, ao ser ressonante com a realidade interna do participante, permite a visualização do cenário de sua condição atual e idealização do que esta buscando e traça planos para a concretização.

LEWIN (1948), MAILHIOT (1981) e MOSCOVICI (2001a) discorrem sobre o processo de maturidade grupal, o que seria a produção efetiva do grupo, quando este conquista um estado de tolerância e aceitação das diferenças individuais, o que permitem a integração e o equilíbrio entre todos os seus membros. Este fato leva as comunicações transparentes e autênticas, que facilita a tomada de decisões conjuntas, que minimizam os conflitos, oportunizam a criatividade, a inovação e a ousadia frente aos desafios das tarefas a serem cumpridas. Finalmente, apresenta resultado desejado com uma produção efetiva. É importante ressaltar que o equilíbrio no grupo é uma de suas fases em que transparecem a abertura e a flexibilidade.

A dinâmica grupal encontra-se em contínuo movimento sempre em processo de um estágio a outro, em fluxo e refluxo, susceptível aos fatores intrínsecos e extrínsecos que impactam sua estrutura e conteúdo e exige do coordenador, atenção a diversos aspectos que exploramos a seguir.

\section{Continência: uma atitude transversal}

A teoria de Heráclito segundo JAEGER (1989) já apontava para o conhecimento de que a vida é um processo de mudança inexorável, contínuo e de fluxo constante. O Ser Humano é vida. Também o Ser Cósmico o é, porque se movimenta e se modifica, sempre, em eterna. JAEGER (1989) relata que para Heráclito a mudança é processo absoluto. $O$ indivíduo não tem opção de escolher se deseja, ou não, mudar. O processo de mudança é contínuo e não pode ser freado nem impedido, portanto a continência a esse movimento é um fundamento básico do coordenador de grupo e por isso tratamos dela em destaquem.

O coordenador que visa processo de mudança precisa observar os diversos estágios inerentes ao percurso do grupo, ciente de que as pessoas mesmo sensibilizadas e conscientes da necessidade de mudar estão sujeitas aos retrocessos, bloqueios, frustrações, pessimismos e resistências.

A ação em direção a mudança não autoriza o seu sucesso. A intervenção só deve acontecer após investigar e diagnosticar o cenário do grupo. É preciso verificar quais os fenômenos psicossociológicos de dimensão macro e micro que determinam a construção da realidade grupal. O comportamento grupal implica em dois pólos: o que a realidade sócio-histórica oferece na construção estrutural e a realidade subjetiva que fornece subsídios para o processo e o conteúdo do grupo.

Cada grupo é portador de um conjunto de crenças ideológicas que norteiam seu discurso filosófico e sua ação. Esse reflete no comportamento apresentado na resolução de conflitos, luta pelo poder, contatos interpessoais, sistema de comunicação, tomada de decisão e políticas que provocam as mudanças e, se manifestam por meio dos símbolos, tradições, rituais, códigos, que transparecem no discurso manifesto e no latente (ENRIQUEZ, 1997).

Para TORRES et al, (2003) é importante também que o coordenador conheça as características relevantes que se manifestam no 
contexto micro, como por exemplo, a forma como o grupo organiza o funcionamento das tarefas, dos procedimentos, normas, leis, regras para o alcance dos resultados, dos projetos, das atividades e as interações entre os participantes do grupo que submergem sentimentos, percepções, motivações, satisfações, emoções.

Sob a luz do movimento interno dos participantes e das condições externas na interação grupal, é que será possível ao coordenador interferir, propondo mudanças. Esta compreensão lhe oferece uma dimensão conceitual que norteia a trajetória da intervenção e delineia uma prospectiva de novos elementos com a finalidade de transformar e renovar os processos do grupo. A compreensão da capacidade de produção do grupo e de sua dinâmica sócio-afetiva, a estratégia do coordenador, o comportamento individual de cada membro no que se refere a sua capacidade de tomar decisão e a flexibilidade, contribuem de modo significativo na maneira em que o indivíduo aceita mudanças, articula uma ação e lida construtivamente com as mesmas (BECHELLI \& SANTOS, 2001, 2002; MOSCOVICI, 1965).

Nesse sentido, é preciso buscar força no próprio processo de mudança, na nucleação e na identidade que o grupo constrói para impulsionar o rompimento dos paradigmas. A força de pertencer a um grupo, de se sentir juntos, cria uma associação de energia. ENRIQUEZ (1997, p. 117) sinaliza que o grupo possui a força da mudança e esta é um compromisso de todos "uma luta só pode ser eficaz se for assumida por um grupo e não por um indivíduo sozinho".

É possível identificar vários pressupostos teóricos no campo psicossocial do grupo, mas não é possível afirmar qual a composição de fatores e em que grau, intensidade e volume fornecem a estrutura da fórmula química que desencadeia o processo de mudança no grupo. No fenômeno que envolve a mudança atuam vários fatores, como: paradigmas incorporados que são as concepções, conjunto de crenças e a percepção da realidade quanto à situação atual e a pretendida, estado de equilíbrio, a instalação ou não da resistência, a intensidade dos elementos que atuam e mantém o comportamento, o volume de hábitos que fortalecem e legitimam suas ações.

Alcançar este propósito perpassa pelo desequilíbrio de campo de forças do grupo, por romper com a estrutura, modificar o conteúdo grupal, interferindo na organização dos processos e nos mecanismos que oferecem sustentação a este modelo de comportamentos incorporados, buscando a reorganização interna com base em novos paradigmas. PEREIRA (1999) identifica três pressupostos da mudança, que são: 1) a inexorabilidade: a vida está sempre fluindo, acontecendo, independente das ações dos indivíduos, do seu consentimento ou do seu desejo; 2) a ambigüidade: a mudança causa um conflito nos indivíduos no momento em que este se defronta com a necessidade de mudar, porque existe apego natural à estabilidade e 3) a perda: "não é possível transitar de um estado a outro sem renunciar a coisa alguma" (PEREIRA, 1999, p. 6).

Nesse sentido a mudança é uma via de mão única, ou seja, o indivíduo ao se tornar consciente da realidade forja um movimento do interno para o externo e toma sua decisão. O nível das forças impulsoras e restritivas no grupo determina a dimensão do equilíbrio, que é o ponto de partida para a mudança. O modelo de pesquisa-ação de LEWIN (1948) demonstra que existem várias forças atuando em diversas direções e estas atuam em quantidades variáveis e em graus diferentes (MAILHIOT, 1981).

As forças atuantes nos campos internos ou externos e os componentes presentes mantêm o comportamento do indivíduo num estado de equilíbrio, assim as forças que atuam no equilíbrio são de dois tipos: Forças impulsoras: que tendem a elevar o nível de atividade do indivíduo com o grupo e Forças restritivas: que tendem a diminuir o nível de atividade.

Ainda partindo desse modelo, MOSCOVICl (2001a) indica que é preciso elaborar alternativas de mudanças e sugere três alternativas: 1) Aumentar a intensidade das forças impulsoras, que, proporcionalmente, aumentariam o grau de intensidade das forças restritivas; 2) Diminuir a intensidade das forças restritivas para alterar 0 equilíbrio, e aí o eu é considerado como uma barreira; 3) Identificar as forças latentes ou neutras que existem na situação ou fora dela, mobilizando-as para atuarem como forças impulsoras que possam promover um desequilíbrio, desencadeando as mudanças favoráveis e desejáveis no grupo.

Quando a proposta é de mudança radical, a situação já estruturada e segura fica ameaçada, ou seja, quando se identificamos as vantagens, fortalecemos as desvantagens. Neste caso, o indivíduo entra em crise e vive um conflito intenso para fazer sua escolha e há manifestações freqüentes de ansiedade, que o bloqueiam. Quando esta atitude ocorre dentro de padrões normais à reação é sadia. A perda de costumes e hábitos já conquistados desencadeia reações imediatas de desconforto, angústia, medo, conscientes ou não, que estão interligados aos paradigmas, aos modelos, cujo grupo, os incorpora e aplica em seu modo de funcionar. A primeira reação é a de restabelecer o equilíbrio anterior.

O processo não é simples, nem imediato e requer um plano de ação a médio e longo prazo, persistência e comprometimento do coordenador com o que está sendo transversalizado. A transformação que pretende ter caráter renovador, transpondo os modelos estabelecidos, necessita que se amplie à percepção das vantagens, enfraqueça as desvantagens e minimize as resistências. Esta postura de intervenção facilita a passagem em direção ao novo comportamento. Mudar um indivíduo 
significa romper suas resistências, possibilitando que ele tenha uma percepção diferenciada do contexto, para criar condições objetivas que o estimule, incentive e desperte em sua subjetividade o desejo de uma ação consciente em prol da mudança.

Não basta a análise reflexiva para garantir a ação. A lógica do discurso e da ação faz parte de um sistema psicossocial. A ação encontra-se interligada por uma composição de forças. O discurso faz parte de um sistema intrínseco construído com base na subjetividade e na condição sócio-histórica do indivíduo. A ação renovadora só acontece quando permeada pela vontade consciente e calcada no seu significado substancial. Quando a fórmula de incentivos apresentada pelo coordenador não contém todos os elementos químicos fundamentais, a resistência pode se instalar. O coordenador é o suporte do grupo, atuando com estratégias que são as "enzimas" desencadeadoras do processo de mudança.

As resistências dependem de como o grupo concebe ideologicamente a realidade, ou seja, como o grupo pensa e interpreta os fatos e compõe para si mesmo significado pessoal do ambiente interno e externo (LEWIN, 1973). As compreensões destes pressupostos devem ser na ótica dialética. A situação de mudança ocasiona novas posturas, inovações, ousadias e gera uma força a ser temida. Surge uma oportunidade a ser aproveitada.

Os incentivos ampliam as perspectivas do novo, do desafio, da ousadia e da criatividade, estes fatores desencadeiam processo em direção a mudança. Aqui são agregadas novas forças impulsoras para promover o desequilíbrio, introduzir desafios que estimulem e incentivam no sentido da mudança para a situação desejada. O coordenador deve ter o domínio de tecnologia para aplicá-las em benefício do desenvolvimento grupal.

Os instrumentos técnicos podem ser jogos, simulações, estudo de caso, textos, filmes, atividade intra, inter ou grupal, exercícios estruturados, atividades semi-estruturadas, a técnica do grupo $\mathrm{T}$, dramatizações, sociodrama, entre outras. A possibilidade do coordenador na escolha dos instrumentos para a elaboração de um plano de atividade são amplas e diversificadas e é permeado pelos objetivos e conteúdo do programa a serem executados.

Além da continência como elemento chave que estrutura a ação do coordenador, alguns aspectos são considerados fundamentais no manejo e condução de um processo grupal como veremos a seguir.

\section{O enquadre do trabalho grupal}

O enquadre se constitui em um conjunto de aspectos inerentes ao processo grupal que o coordenador precisa estar atento quando se prepara para desenvolver um trabalho com determinado grupo. É passo fundamental ao sucesso da atividade, uma vez que prevê uma série de detalhes que compõem o enquadramento e adequação do que o grupo precisa para atingir os objetivos propostos, ao mesmo tempo em que dá subsídios ao coordenador para uma atuação mais efetiva:

a) O planejamento: este deve ser meticuloso, detalhado e, sobretudo, respeitar o grupo. É fundamental fazer um mapeamento, aplicando o processo de pesquisa-ação de LEWIN (1948), detectando as individualidades, singularidades, experiências, os símbolos cultuados, os rituais realizados, as ideologias presentes. Esta análise de contexto traz a dimensão global da dinâmica que o grupo está apresentando no momento. O diagnóstico é o sensor da elaboração das atividades a serem realizadas e deve estar em sintonia com o movimento do grupo, além de nortear o coordenador na identificação dos recursos e tecnologias apropriadas à utilização dos instrumentos mais propícios para a intervenção.

A elaboração do planejamento permite analisar, prever as diversas possibilidades de respostas do grupo e abrange as diversidades que poderão ocorrer. Qualquer situação que se apresente, poderá ser processada. O coordenador não pode hesitar em mudar o planejamento se perceber que o grupo não está preparado e nem disposto a fazer o exercício proposto ou mesmo quando o movimento do grupo demanda outra atividade. Faz parte do planejamento a consideração de todas as hipóteses possíveis que ocorram na dinâmica grupal, durante a atividade, bem como verificar a mais eficaz a ser adotada, diante as situações. Na escolha da técnica o coordenador deve estar atento ao movimento grupal, para não propor atividade em que haja confronto ao que 0 grupo está sentindo e vivendo.

Quando as técnicas não harmonizam com a sinergia grupal ocorre uma cristalização da situação atual, sem que haja evolução no sentindo da conquista da maturidade grupal. Se o material processado não for pertinente ao objetivo traçado, o grupo vivencia experiências, que pode até agregar um crescimento pessoal, mas não contribui para o alcance dos objetivos que foram estabelecidos.

b) Aquecimento: antes de iniciar uma atividade ou passar de uma atividade para outra, é importante aquecer o grupo, preparando-o e direcionando sua energia para a tecnologia a ser aplicada. A técnica aplicada deve ser condizente com 0 assunto a ser utilizado, evitando que o grupo vivencie movimentos ambivalentes. Por exemplo, quando o aquecimento é de contato e em seguida, aplica uma atividade de competição, separação ou divisão.

O aquecimento pode servir também como vitalizador. Neste caso, o ideal é utilizar técnicas 
que movimentam, com músicas alegres e vibrantes, que tenham cores e que despertam e estimulam os participantes para a próxima atividade. Aquecimento com técnica que precede atividade introspectiva deve privilegiar a mobilização de aspectos intrapessoais. É positivo o uso de técnicas com materiais coloridos, que enriquecem a produção criativa, possibilita o exercício de fantasia, onde cada membro do grupo constrói sua própria vivência interna ou ainda, atividades que mobilizem a energia do grupo, como aquelas com músicas e com movimento do corpo (ANZIEU, 1983).

c) O trabalho teórico: para o trabalho de conteúdo teórico é fundamental o aquecimento do grupo com atividades de movimento que despertam o corpo do estado de letargia. Geralmente devemos solicitar ao grupo que faça um círculo exato, de modo que os membros aproximem-se uns dos outros, o que evita a sobreposição dos participantes ou filas paralelas. A luz amarela ou pouca luz provoca estado de sonolência, então, quando utilizamos filmes, projeções de slides, transparências, data show, não devemos apagar todas as lâmpadas. É preciso manter alguma claridade. A exposição de material teórico dá oportunidade ao grupo para fazer questionamentos por meio de perguntas, assim é importante criar situações que dêem oportunidades aos participantes intervirem de forma interativa na exposição. O coordenador atento preocupa-se para as manifestações corporais dos participantes, as quais funcionam como um sensor que comunica se a exposição está ou não agradando aos expectadores.

\section{O manejo de situações previsíveis no contexto grupal}

Outro aspecto fundamental no trabalho do coordenador é alicerçado no manejo de situações comuns no contexto grupal, que envolve tanto o grupo como a pessoa do coordenador e podem ser pensadas de modo a tornar seu trabalho mais eficiente e adequado às necessidades do grupo, as quais serão apresentadas a seguir.

a) Evitar atitudes de interferências no processo do grupo é fundamental para a garantia de resultado que consideramos ideal no seu manejo. O contrário seria uma agressão à individualidade do grupo. O movimento do grupo traduz o modo como este pensa, sente diante da sua relação com os fenômenos que o afetam. 0 comando da atividade a ser realizada não deve ser diretivo, induzindo ou determinando o que será feito por cada pessoa. Não cobramos a participação nomeando quem deve executar a tarefa. O que podemos é estimular a participação por meio de técnicas de aquecimento, acompanhando seus desdobramentos nos debates, nas trocas de idéias e experiências, nas análises, reflexões, divisões das funções e ainda na forma como o grupo opera, organiza e processa as atividades e apresenta o resultado.

b) A dimensão pessoal do coordenador diante do trabalho com o grupo deve ser preservada, sendo fundamental que o coordenador tenha clareza da necessidade de não se expor física e emocionalmente perante o grupo suas inseguranças, receios, medos e contradições. A ótica pelo qual o coordenador percebe o mundo, assim como suas certezas e incertezas, opiniões, valores, conceitos, preconceitos, paraconceitos, contradições internas e concepções de vida, deve estar sob seu domínio. É fundamental que ele saiba manejar suas dificuldades para não se expor ao grupo. Da mesma forma, deve cuidar para garantir segurança diante da teoria, competência técnica, interpessoal e habilidade de saber fazer para acompanhar toda a temática manifesta no grupo, tendo uma visão panorâmica e abrangente que consegue atuar de forma vertical e horizontal nos fenômenos que estão ocorrendo no universo grupal.

O coordenador não se posiciona a favor ou contra a situação grupal, nem faz defesas de crenças e códigos morais, nem discorre sobre princípios ou concepções do que é certo ou errado, nem emite julgamentos sobre as manifestações do grupo. Distingue entre suas convicções morais, políticas, religiosas, sociais e as do grupo, estabelecendo um hiato não permitindo que os seus conceitos interfiram e venham a transgredir a conduta ética. Verbalizar crenças e opiniões demonstra uma postura unidimensional que permite a discriminação, o preconceito e culminam numa interferência intencional no direcionamento do grupo atendendo aos seus interesses.

É certo que os coordenadores não são seres assexuados, nem extraterrestres, e ainda, possuem vários sentimentos que surgem do processo de estar presente no espaço grupal. A forma de lidar com estes elementos determinam sua conduta ética, de se manter com a postura de quem percebe e analisa sem estar diretamente envolvido. É importante o coordenador estabelecer vínculos com o grupo, com os devidos cuidados para não criar laços afetivos que os distancia do seu real trabalho. Isso certamente leva o grupo a vivenciar um estado de dependência e de caos (BION, 1975).

O coordenador naturalmente tem a expectativa de que todos participem. Entretanto, há os que dormem, os que discordam, os que relaxam, os que questionam, os que riem, os que se atrasam, os que não querem mudar, os que não querem aprender, os que conversam paralelamente, os que burlam as regras do contrato, os que não participam, os que 
confrontam, os que sabotam as atividades, os que ficam em silêncio.

Os grupos, também manifestam comportamentos de agressividade com 0 coordenador ou outros membros, de disputa pelo
poder para conduzir o grupo, de se envolver em outras atividades não pertinentes ao objetivo da tarefa, de ignorar o facilitador ou o conteúdo do programa, de avaliar o treinamento comparando as situações de fora do círculo grupal, de chegar ou se retirar quando lhe for conveniente.

A manifestação desses diferentes tipos de comportamentos, bem como a instalação de múltiplas fontes de resistências pode suscitar no coordenador sentimentos de frustração, incompetência ou insegurança. O desejo advindo de situações, como os exemplos trazidos até aqui, é de utilizar o poder para revidar ou repreender publicamente aquele(s) membro(s) ou mesmo forçar o grupo agir conforme a sua vontade. No entanto, faz parte do papel do coordenador apreender 0 significado de tais atitudes e de utilizar o seu conhecimento holístico a respeito do ser humano e do funcionamento de grupo, para lidar com cada situação, em particular Destacamos, ainda que o respeito deva permear sua atuação em todos os momentos e de igual forma os membros do grupo devem se comportar, a tolerância para as formas desrespeitosas e rudes de tratar o coordenador e outras pessoas deve ser limitada.

A teoria de BION (1975) demonstra que quando o grupo diverge da atitude do coordenador, pode estar sinalizando que está requisitando a presença do pai autoritário e/ou protetor, buscando proteção e segurança, demonstrando seus receios, medos e confusão interna de não ser capaz de tomar suas decisões com a confiança e eficácia necessária para atingir os resultados. O coordenador atento a estes movimentos deve evitar atuar complementando o desempenho do grupo. Os ensinamentos de Bion expressam com clareza o quanto é importante estar atento para não permitir que se instale no grupo uma situação de dependência. Atitudes de proteção, de compreensão, de autoridade ou mesmo de um afeto excessivo por parte do facilitador, obscurecem e atrapalham o desempenho grupal. Mantêm a dependência, confirmando a cada participante sua incapacidade, cristalizando suas inseguranças.

É preciso respeitar o tempo interno de cada membro para o processamento de seu aprendizado, aceitando as individualidades e tolerando as diferenças, sendo flexível nas manifestações e atitudes diferentes de suas crenças pessoais. É como um jardineiro que prepara o terreno, orientando as pessoas para que escolham o que será plantado, onde plantar, como e quando é a época mais propícia para as sementes germinarem, ou seja, este suporte fortalece o universo grupal. Depois deste preparo do terreno, a rega com nutrientes, que são os fundamentos teóricos, os pressupostos e os modelos de compreender a realidade, completa o trabalho. No entanto, somente o grupo pode escolher a semente que será plantada.

Os resultados a serem alcançados são determinados pela semente plantada: mangueira, pequizeiro, parreira ou um pé de alface. O indivíduo ou o grupo serão os responsáveis para cuidar da planta. A qualidade da árvore e seu fruto vão demonstrar no futuro que cuidados ou não, teve cada participante com o cultivo da semente escolhida. A semente pode nem mesmo germinar. $O$ comportamento de mudança pode ser observado na maior ou menor quantidade e qualidade da árvore e fruto colhido. Neste universo quântico tudo é possível e se converge para o mesmo centro (MOSCOVICI, 1996).

Quando o coordenador trabalha as resistências do grupo precisa estar atento à forma como verbaliza no grupo que este está com resistência pode soar como uma acusação e gerar no grupo a necessidade de se proteger negando, ou até mesmo, consolidando o comportamento, isto é, expressando que existe resistência propicia a instalação de outros mecanismos de defesa (FREUD, 2003). É importante sim, expressar o comportamento que está ocorrendo e tentar conjuntamente com o grupo averiguar as causas, identificar os motivos que levou o grupo a agir desta forma. Nesse sentido devemos evitar o uso de conceitos de resistências, mas mostrar ao grupo suas atitudes, levando-o a refletir sobre suas escolhas. Esta é uma situação normal, faz parte do processo grupal. Neste caso, o substancial é promover a reflexão e não padronizar ou enquadrar comportamentos em teorias estruturadas.

O uso adequado de técnicas é um aspecto dilemático para o coordenador, pois leva o grupo à exposição de sentimentos, que nem sempre são continentes ao que está sendo vivido. O intuito de suscitar emoções ou, ao contrário, aplicar uma técnica que ignore o que o grupo está sentindo pode ser bastante arriscado. Estas atividades instalam um movimento de fuga da situação grupal, reafirmando o processo do grupo de luta-fuga que é a permissão para que haja negação dos sentimentos e, conseqüentemente, a instalação de um conflito velado. Quando o conflito não é processado impede a sinergia e a produtividade grupal (BION, 1975). Andaló $(2001 ; 2006)$ já nos alerta quanto ao uso de técnicas durante o processo grupal, recomendando que isso deve ser cuidadosamente planejado. Mesmo assim, dependendo do momento do grupo, pode não ser o melhor que o coordenador tem a fazer, em particular, quando esse planejamento é fechado, feito com antecedência e não considera o momento atual do grupo ou não faz uma leitura adequada do mesmo.

O comando das atividades a serem executadas deve ser claro e objetivo, esclarecendo o que é permitido e o que não é permitido. Mediante as regras da atividade o grupo se articula conforme seu movimento interno. O papel do coordenador frente às 
atividades é de ouvinte atento, sem expectativa de resultados, estando aberto para aceitar o produto que venha do grupo, mas alerta para não ceder aos seus desejos de fazer parte dele ou de se deixar seduzir para que este o aceite, sendo "amiguinho" do grupo. Segundo o pressuposto de Bion (1975) esta permissividade fixa o grupo no processo de dependência.

Um coordenador que conhece a sua tarefa deve compreender que não existe grupo não autêntico, grupo bonzinho ou grupo ruim. Os comportamentos manifestos no grupo expressam a sua verdade. Para ANZIEU (1983) "o grupo é e é causa sui' (p.75), isto é, o grupo vivência no processo grupal o que é possível viver.

Ao apresentar uma análise teórica das vivências do grupo, o coordenador não deve recorrer a recursos comparativos com outros grupos coordenados anteriormente, mostrar resultados conquistados em outras situações ou relatar vantagens obtidas. Deve ser evitada a exposição de relato de outras experiências, que de acordo com seu critério, tiveram resultados positivos, evidenciando o intuito de ser premiado ou o desejo de adquirir vantagens junto ao grupo. Esta conduta propicia a fuga dos propósitos e do contexto da realidade grupal, o que caracteriza uma luta-fuga da situação a qual estar sendo vivenciada.

O relato de suas conquistas anteriores são argumentos antiprofissionais que demonstram imaturidade e evidencia incompetência na condução de grupos. Revelam ainda, que o coordenador adquiriu habilidades para conquistar o grupo por meio da condição de ser coordenador. Tal comportamento traz conseqüências irreversíveis para o crescimento do grupo, que só acontece pela construção de uma relação de interdependência, nutrida pelo vínculo profissional que culmina na separação do coordenador. Este oferece o suporte necessário, todavia permite que o grupo construa sua própria identidade, pelo fortalecimento dos seus laços, alianças e afinidades que afloram na convivência intensiva entre seus membros. Ao permitir a sinergia grupal, o coordenador possibilita a produção, a criatividade, a tomada de decisão e a iniciativa de colocar em prática suas ações planejadas.

Outro cuidado do coordenador quando utiliza técnicas é evitar aquelas que ridicularizam os membros do grupo. $\mathrm{O}$ aprendizado coletivo pressupõe aprender a dar ajuda, crescimento integrado por meio de experiência compartilhada e que, às vezes, independe do conteúdo da tarefa (MOSCOVICI, 1996). É um processo de buscar e conseguir recursos e informações para solucionar os problemas, com e através das outras pessoas. O uso de técnicas que discrimina, humilha, expõe ou ridiculariza causam um desequilíbrio nos participantes e, de acordo com a intensidade, pode ocasionar uma situação ameaçadora, com sentimentos de receios e medos. Esta vivencia pode romper com elo de confiança do grupo e colocar em risco a credibilidade do coordenador, que quebra o clima de transparência e integração, fundamental para o processo de aprendizagem.

Esse movimento pode desencadear ainda, um processo de fragilidade emocional no participante, não provenientes do exercício e da proposta de trabalho em grupo. Tal atitude do coordenador serve de válvula que aciona o imaginário grupal, criando uma expectativa de quem será o próximo a ser exposto perante todos. O grupo para se preservar utiliza mecanismos de defesas, com desconfiança, hesitações, precaução e resistência, (ANZIEU, 1983; PILON, 1987). Uma vez estabelecida esta defesa o coordenador encontrará dificuldade de desenvolver suas atividades, o que interfere no processo de aprendizado.

De igual forma, é fundamental evitar a proposição de situações que não poderão acontecer ou que o grupo não pode vivenciar, tais como tarefas com prêmios que não poderão ser oferecidos. Exemplo: agora o grupo irá realizar uma tarefa e o vencedor vai ganhar uma viagem a Paris, ou ainda: deixe o desânimo no bolso, deixe a tristeza em casa.

O uso de recursos didáticos como cera, massa de modelar, pintura com tinta, argila, pode mobilizar conteúdos primitivos de imagens internas e subjetivas. O movimento do grupo é projetivo, o que leva cada membro a uma vivência intrapessoal, remete o participante a si mesmo, evocando emoções mais intensas e profundas. Quando o coordenador opta por tais recursos, tem que ter clareza de que será necessário estar atento aos conteúdos inconscientes dos participantes e da fantasia grupal, bem como permitir que as emoções fluam como processo terapêutico (ANZIEU, 1993).

Nesse caso, devemos solicitar que cada participante expresse suas reflexões na realização da tarefa e quais são os sentimentos no momento, mas alertando que esse não é espaço de psicoterapia. Quando o coordenador é claro nos objetivos da tarefa, estabelece limites ao verbalizar seu comando, o qual delimita o que será processado e, caso ocorra algum momento de fragilidade 0 próprio grupo oferece apoio e o suporte necessário para o participante.

Se necessário, o coordenador pode sugerir ao participante apoio psicoterápico, mas deve esclarecer que o contexto é grupal e, portanto, não adequado para analisar as individualidades de cada participante. Normalmente, quando um grupo vive uma experiência que mobiliza conteúdos projetivos verbaliza uma fala curta, objetiva e bastante sucinta. Neste caso o tempo previsto para a realização da tarefa não deve ser amplo.

Finalmente, e ainda relacionado ao uso das técnicas ressaltamos cuidado ao propor atividades comensais, tais como oferecimento de biscoitos, balas, chicletes, chocolates. Esses são recursos que exigem que o coordenador ofereça um tempo para que os participantes saboreiem os mesmos e só 
depois retomem a atividade. Neste caso, pode atrapalhar a atividade. As técnicas com alimentos envolvem as necessidades primárias e está representando no grupo o desejo de buscar fora outros conhecimento ou "alimento" para suprir suas necessidades. O coordenador atento não se permite ser seduzido pelo grupo e nem aceita estas situações (BION, 1975). O alimento seja teórico ou comestível, não deve ser oferecido além da necessidade de cada um. A proteção excessiva permite dependência. O ideal é que se o grupo deseja se alimentar fisicamente, que o faça em um tempo combinado, fora do contexto da técnica.

A luz e a sombra dos grupos são os aspectos concretos e simbólicos, objetivos e subjetivos, visíveis e invisíveis que acompanham a vida grupal (MOSCOVICI 2001, 2001a). Segundo essa autora, os aspectos sombra são representados pelos elementos simbólicos, subjetivos, invisíveis, que são ignorados, desvalorizados, minimizados, que ficam no escuro, permanecem intocados, como se não existissem e nem tivessem influência sobre o grupo. Já os aspectos luz incluem tudo aquilo que é objetivo, focalizado, em que se acredita que é valorizado, que é incrementado e que é considerado como realidade. No processo de grupal é importante que o coordenador esteja atento a ambos os lados que surgem das interações entre os membros, pois é exatamente isso que lhe dá a leitura correta do que vive o grupo, ou seja, as diversas facetas e possibilidades.

Segundo MOSCOVICl (2001), o reconhecimento e manejo do lado luz e sombra dos grupos é aspecto complexo da tarefa do coordenador, que exige prática, sensibilidade, sobretudo, competência técnica e interpessoal para lidar com a polaridade humana.

\section{A administração do tempo}

Esse é um aspecto que, quase sempre, causa muita angústia ao coordenador. As atividades devem ser iniciadas e terminadas no horário estabelecido no contrato. Os membros de grupo atrasados devem ser inseridos na sala de acordo com as etapas de cada atividade, sem repreensão, sem criticas e ainda, com um discurso pró-ativo e receptivo que integre 0 membro atrasado, embora ele possa ficar observando caso a atividade não permita sua inclusão.

O monitoramento deve ser feito pelo coordenador e, se este está acabando este pode utilizar alguns recursos como: solicitar às pessoas que sejam mais sucintas e objetivas na realização da tarefa; analisar seu planejamento e refazendo, retirando atividades, diminuir o tempo previsto para cada atividade a ser aplicada, ou se nenhuma tentativa anterior der certo fazer um recorte na cena grupal e renegociar o horário. Neste caso, devemos buscar a adesão de todos, propondo que seja ultrapassado o horário ou propondo outro dia ou outro horário para o término das atividades.

Ao interromper a tarefa o coordenador deve ter uma proposta pronta para evitar prolongamento de discussão e polêmicas que afetem ainda mais o tempo. No entanto, deve se lembrar da existência do contrato e de que não deve mudar as regras sem a permissão prévia do grupo. A quebra de contrato abre oportunidade para que o grupo burle as normas de acordo sua conveniência. A postura do coordenador é a referência para a garantia do contrato firmado no grupo.

Em caso de planejar técnicas lúdicas prever um tempo mais longo para o uso de materiais de jornal e revistas para recorte e construção de painéis, que causam momentos de descontração e abrem oportunidade para os participantes folhearem o material com interessem em outros temas e ainda para aquelas que requeiram criatividade como desenho, elaboração de materiais e objetos.

Quando utilizamos atividades de textos estruturados, discussão de filmes, a opção é incluir no planejamento atividades estruturadas ou semi estruturadas em tempo limitado, pois estimulam a participação adequada ao conteúdo programado com possibilidades de comportar o tempo previsto.

De igual forma é necessário atenção quando trabalhamos com grupos com participantes que apresentam um aprendizado em espaço e tempo diferente, que operam uma mesma tarefa em tempos diferentes, acelerando ou diminuindo a atividade. Nesse caso, é preciso administrar o tempo com o grau de ansiedade de cada participante, pois existem os que terminam antes, como os que ultrapassam o tempo previsto. Quando o subgrupo acelera a tarefa, esta pode não ter sido verticalizada ou realizada de modo superficial. Por outro lado, quando o grupo ultrapassar o previsto, pode estar encontrando dificuldade de assimila ou de apresentar uma síntese do trabalho, o que significa dizer que o grupo está vivenciando momentos de luga-fuga (BION, 1975; SAMPAIO, 2002). Em ambas as situações a percepção, a vivência e a sintonia do coordenador com o grupo é que irá determinar sua atuação.

\section{O manejo do conflito no grupo}

O conflito nas interações grupais geralmente é explicitado pelas atrações e rejeições interpessoais. São alicerçados nas concepções diferentes de como cada participante constrói seu próprio sistema de conceitos, símbolos, imagens, julgamentos e controle grupal. Quando existem posicionamentos contrários entre os membros eles manifestam tensões e desacordos. Ao surgir estas polaridades podem ocorrer casos de atritos diretos, agressões verbais ou físicas, opiniões enfáticas, polêmicas e competições entre os participantes ou mesmo com o coordenador. O grupo vive o movimento de luta-fuga segundo BION (1975) e é oportunos que sejam verbalizadas as tensões, os conflitos e evidenciadas 
as idéias e sentimentos divergentes, permitindo que cada participante se expresse em defesa de seu ponto de vista, garantindo a singularidade de cada ser. É importante que a discussão permaneça em nível verbal sem agressões físicas.

Sempre que um grupo vive essa situação toda sua energia fica centralizada no conflito, o que bloqueia o desenvolvimento grupal. O próprio grupo precisa resolver seu conflito, o coordenador não toma partido, nem discute com os membros do grupo, nem faz intervenções diretamente na situação. Entretanto, não ignora e nem faz de conta que nada está ocorrendo. O indicado é fazer um recorte na situação grupal e instalar uma plenária, mostrando e clareando as situações que estão ocorrendo, permitindo que o grupo entre em contato com sua realidade, que é o conflito. Ao observar o cenário e destacar os diversos códigos e diferentes concepções compartilhados nas interações, o coordenador garante a pluralidade e a expressão de cada membro do grupo, sem que prevaleçam conclusões absolutas.

Como já relatado em outro momento, não faz parte da competência do coordenador apresentar posições sobre o que é correto ou errado ou que deve ser seguido por todos. A situação deve ser administrada de modo que o grupo consiga transpor estas tensões decorrentes do convívio interpessoal, superando a situação. O pensar diferente dos membros de um grupo não obstrui o processo grupal, pelo contrário, assegura o debate, permite que o grupo tome consciências de suas diferenças, dificuldades, voracidades, competições e exigências, provocando reflexões e análises, o que garante o respeito e o fortalecimento do grupo por meio da aceitação das individualidades e diferenças de cada participante. Se o conflito for com a coordenação é preciso que seja evidenciada para o grupo as cobranças, imposições, exigências e competições com o coordenador.

\section{O poder do contrato grupal}

O ultimo aspecto tratado por nós, entre aqueles que acreditamos amparar a ação do coordenador de grupos é o contrato grupal. Vários autores discorrem sobre sua importância e fazem recomendações do que nele deve constar (OSÓRIO, 1989; CASTILHO, 1994; MUNARI \& RODRIGUES, 2003; ZIMERMAN, 2000; COREY \& COREY 2006; COREY et al, 2004; NAPIER \& GERSHENFELD, YALON \& LESZCZ, 2004). Entretanto, acreditamos que mais do que regra de um contrato de trabalho está a atitude comprometida e respeitosa do coordenador para com o grupo, seu crescimento e sua criatividade.

MOSCOVICI (1965) sinaliza alguns aspectos que devemos considerar quando pensamos no contrato grupal, pois, para a autora, em torno do contrato devemos considerar que ele é um instrumento que o coordenador possui a seu favor
Ihe assegurando o comprometimento grupal. Afirma ainda que toda convivência humana necessita de limites, que uma vez estabelecidos irão delimitar o espaço de cada pessoa e assegurar que todos os membros de um grupo sejam respeitados. O contrato não deve ser feito pelo coordenador e imposto ao grupo, mas elaborado conjuntamente. Portanto, para sua construção é necessária postura ética, respeito, responsabilidade, comprometimento, capacidade para ouvir, flexibilidade para ceder e confiança entre todos e perante todos. Ao tratarmos horários, metodologia, intervalos, lanche, material utilizado, programação, faltas, deveres e direitos dos alunos e do coordenador, assiduidade, pontualidade, normas, regras, é fundamental esclarecer o que será ou não permitido, pois assim o contrato não será imposto, mas um conjunto de responsabilidades conjuntas.

Finalmente, o contrato pode ser reavaliado sempre que cada membro ou o coordenador sentir desconfortável diante algum aspecto acordado ou que transpareça indicadores que necessite de mudança. Assim, ao descumprimento de qualquer cláusula, não é exigido que seja, necessariamente, o coordenador a tratar do assunto. Qualquer membro do grupo pode cobrar o cumprimento do contrato ou a rediscussão do mesmo.

\section{CONSIDERAÇÕES FINAIS}

Na tentativa de fazer uma reflexão sobre os pressupostos, principais dilemas do coordenador de grupos e apontar alguns elementos que pudessem ajudar os profissionais que tem no grupo seu campo de trabalho, vislumbramos a complexidade dessa tarefa no contexto do trabalho em qualquer área, mas reconhecemos sua importância, especialmente, para aqueles que atuam no campo da saúde e da educação.

Todas as diretrizes que amparam as políticas públicas de saúde e educação são enfáticas sobre a relevância do preparo de profissionais para o desenvolvimento de habilidades no manejo grupal. Sem dúvida alguma, isso tem significados objetivos, se pensarmos na dimensão coletiva do trabalho nessas áreas, daí a importância do desenvolvimento técnico, mas, sobretudo, na relevância da dimensão subjetiva da interação humana que tem influenciado os rumos da humanidade. OSÓRIO $(2000,2003)$ é enfático ao afirmar que estamos na era da grupalidade.

Isso nos remete a compreender as dimensões do círculo sagrado, ou seja, o significado de círculo sagrado que em sânscrito é o mesmo que mandala, que é a representação do todo. Simboliza o ausente, o inconsciente e suas dimensões perdidas de imagens, mitos, ritos e de signos. Contemplam também, o presente, o momento, o consciente e o encontro inteiro, profundo e pessoal do eu-tu dentro da concepção de BUBER (1974). Segundo MOSCOVICI (1996) este espaço holográfico, permite que o tempo, o espaço e o ritmo prevaleçam juntos, 
numa síntese viva, orgânica, espiritual, material, emocional e ecológica sempre em movimento.

O círculo fez parte dos rituais e costumes de nossos ancestrais, desde a pré-história. O homem primitivo reunia-se em círculo, ao redor de uma fogueira: aquecia e afastava os demônios. Viviam em grupo para garantir a sobrevivência, a segurança e a manutenção das espécies, Acreditavam que através da energia emanada entre as pessoas que compunham a roda, os maus espíritos eram afastados e os bons ali permaneciam (LOMMEL, 1978). Este diagrama circular vem nos acompanhando ao longo da história nas rodas cantadas, na forma da lua cheia, do sol, da terra, da bola.

No trabalho com grupos é preciso ter uma perspectiva da magia do círculo, em que cada parte do mosaico, ainda que diferente, forma um cosmograma, pois a unidade e o todo prevalecem. Mesmo que ao centro haja um espaço aparentemente vazio, é nele que o grupo adquire forma, preenche e delineia suas relações, estabelecendo a dinâmica do encontro eu-tu, (BUBER, 1978). Neste encontro eu-tu predomina uma interação que envolve 0 ambiente, o comportamento e atitudes do eu e do outro. Como o fluxo de energia é contínuo a possibilidade de vir-aser está presente no tu e encontra ressonância no eu. Assim, reforça as potencialidades do ser, pois o círculo é também, o número zero, o início, o que pode ser manifesto ou iniciado. Nessa direção, confirma o outro como uma pessoa capaz, propiciando o desenvolvimento interior e criativo que alimenta na alma do outro aquilo que reconhece em si mesmo. Como afirma ENRIQUEZ (1997, p17) "só o outro pode reconhecê-lo como portador de desejos e garanti-Ihe seu lugar na dinâmica grupal".

O outro deixa de ser apenas uma impressão e transpassa para um plano que amplia e expande a troca de conhecimento, o compartilhar a experiência e a vivenciar as interações entre todos os membros presentes. A singularidade de cada um é reconhecida e respeitada em sua total expressão dinâmica. A energia grupal é capaz de trazer a luz o que permanece dentro de cada um de seus membros (ANZIEU, 1983). Quando nos reunimos em círculo é possível visualizar a todos numa mesma dimensão, perceber e identificar por meio de um olhar todos os membros, os que estão perto e os mais distantes. A racionalidade da burocracia hierarquizada perde o seu sentido, pois não há o primeiro e nem o último, todos adquirem importância, estão à mesma distância do centro e, mantêm a unidade e a totalidade. Neste encontro circular em que se dilui a figura central da autoridade e do líder, estabelece-se um processo democrático e plural que transpira confiança.

A sinergia está na representação circular da mandala, na unidade, na singularidade representada no ser e no encontro eu-tu. Esta alquimia gerada no grupo e compartilhada pelo grupo é capaz de transformar cada pessoa ali presente e o ambiente circundante, (LEWIN, 1948). Este universo vivo, onde emergem as relações estabelecidas no círculo grupal, complexo e misterioso, fascinante, consciente e inconsciente provoca o exercício do imaginário e da magia. A força grupal precede o tempo sóciohistórico da modernidade e, perdura e transversaliza os séculos e as dimensões cósmicas (ANZIEU, 1983; ENRIQUEZ, 1997; LEWIN, 1948).

Nesse sentido, é fundamental ao coordenador a noção da complexidade grupal, para que diante de sua singularidade possa viver o grupo e tudo o que dele emana.

\section{REFERÊNCIAS BIBLIOGRÁFICAS}

ANDALÓ, C.S.A. O papel do coordenador de grupo. Psicologia USP. v. 12, n. 01, p. 135-152, 2001. Mediação grupal: uma leitura históricocultural. São Paulo: Agora; 2006.

ANZIEU, D. O Grupo e o inconsciente. 1. ed. São Paulo: Casa do Psicólogo, 1983.

BECHELLI, L.P.C.; SANTOS, M. A. Psicoterapia de grupo: noções básicas. Ribeirão Preto: Legis Summa, 2001.

BECHELLI, L.P.C.; SANTOS, M. A. Psicoterapia de grupo e considerações sobre o paciente como agente de mudança. Rev. Latino-Am. Enfermagem. v. 10, n. 3, p. 383-391. 2002.

BION, W.R. Experiência com grupos. São Paulo: Universidade de São Paulo, 1975.

BUBER, M. Eu e tu. São Paulo: Editora Moraes, 1974.

CASTILHO, A. A Dinâmica do trabalho de grupo. Rio de Janeiro: Qualitymark, 1994.

COREY, M.S; COREY, G. Process and practice groups. Belmont: Thomson Brooks Cole, 2006.

COREY, G.; COREY, MS.; CALLANAN, P.; RUSSEL, JM. Group Techniques. Belmont: Thomson Brooks Cole, 2004.

ENRIQUEZ, E. A organização em análise. Petrópolis: Editora Vozes, 1997.

FREUD, S. Além do princípio do prazer. Rio de Janeiro: Imago, 2003.

JAEGER, W.W. Paidéia: a formação do homem grego. São Paulo: Martins Fontes, 1989.

LEWIN, K. Dinâmica de grupo. São Paulo: Cultrix, 1948.

LEWIN, K. Princípios de psicologia topológica. São Paulo: Cultrix, 1973.

LOMMEL, A. A arte pré-histórica e primitiva. São Paulo: Enciclopédia Britânica do Brasil Publicações Ltda, 1978.

MAILHIOT, G. B. Dinâmica e gênese dos grupos. São Paulo: Livraria Duas Cidades, 1981.

MOSCOVICI, F. Laboratório de sensibilidade. Rio de Janeiro: Fundação Getúlio Vargas, 1965.

, F. Renascença organizacional. Rio de

Janeiro: José Olympio, 1996.

F. A organização por trás do espelho.

Rio de Janeiro: José Olympio, 2001. 
F. Desenvolvimento interpessoal. Rio de Janeiro: José Olympio, 2001a.

MUNARI, D. B.; RODRIGUES, A. R. F. Enfermagem e Grupos. Goiânia: AB, 2003.

NAPIER, R.W.; GERSHENFELD, M.K. Groups: theory and experience. Boston: Houghton Mifflin Company, 2004.

NICHOLS, K.; JENKINSON, J. Leading a support group. New York: Chapman and Hall; 1991.

OSÓRIO, LC. Grupoterapia Hoje. Porto Alegre: Artmed, 1989.

OSÓRIO. L. C. Grupos: teorias e práticas acessando a era da grupalidade. Porto Alegre: Artes Médicas Sul, 2000.

OSÓRIO, LC. Psicologia grupal: uma nova disciplina para o advento de uma nova era. Porto Alegre: Artes Médicas, 2003.

PEREIRA, M.J. B. L. Na cova dos leões. São Paulo: Markron Books, 1999.
PILON, A. F. Relações humanas com base em dinâmica de grupo em uma instituição de prestação de serviços. Rev. Saúde Pública, v. 21, n. 4, p. 348353, 1987.

SAMPAIO, J. R. Bion`s group dynamics and the work organizations. Psicol. USP. v.13, n.2, p. 277-291, 2002.

TORRES, H.C.; HORTALE, V.A.; SCHALL, V. A experiência de jogos em grupos operativos na educação em saúde para diabéticos. Cadernos Saúde Pública. v. 19, n. 4, p. 1039-1047, 2003.

VECCHIO, E. A. Entrevista psicológica e o psicodiagnóstico. São Paulo: Livraria Sulina, 1975.

YALON, ID; LESZCZ, Psicoterapia de grupo: teoria e prática. Porto Alegre: Artes Médicas Sul, 2006.

ZIMERMAM, D. E. Fundamentos básicos das grupoterapias. São Paulo: Artmed, 2000.

Texto recebido em 20/03/2005

Publicação aprovada em 30/04/2006 